\title{
University-Industry Collaboration Mode Research of ERP Informatization Talents Training
}

\author{
Chuanlin Huang ${ }^{1, a}$, Weiwei Chen ${ }^{1, b}$, Qisong Zhang ${ }^{1, c}$ \\ ${ }^{1}$ Department of Information Technology and Business Management, Dalian Neusoft University of \\ Information, Dalian, 116023, China \\ aemail: huangchuanlin@neusoft.edu.cn, bemail: chenweiwei@neusoft.edu.cn, cemail: \\ zhangqisong@neusoft.edu.cn
}

Keywords: ERP; talent training; university-industry collaboration

\begin{abstract}
With the promotion and popularization of the ERP application, there is a serious problem in the supply and demand of applied talents between information-based enterprises and higher education institutions. University-industry collaboration became the basic method of solving the problem. Based on the present condition and the characteristics of the ERP informationized talents demand, this article researches its university-industry collaboration code, establishes a new innovation system to cultivate the human capacity that the ERP industry needed and the university-industry collaboration integration design of informationized talents training.
\end{abstract}

\section{Introduction}

From late1980s, our country got started to a rapid development of information society. With the development of PC and Internet, the knowledge economy era became more and more globalized, digitalized and cyberized; information technology intensified the competition intensity of the enterprise. In the face of the rapidly changing market, now, the enterprise in order to deal with the global challenges, they must solve two problems quickly, the first is how to establish the efficient and quick reaction mechanism and the second is how to optimize and allocate the enterprise resources adequately. So, the ERP that embodies modern advanced management idea emerged as the time require. The management modernization tide which the ERP as the main tool let Chinese enterprise open a door to the world.

However, the competition in the modern enterprise is the manpower competition, for enterprise, the ERP talents are the most important asset and the heart and soul in the process of enterprise information-based construction, even the crucial foundation for development of industry. So, it is imperative to establish an excellent ERP talents team.

\section{The Present Condition of ERP Talents Cultivation}

According to the task of the enterprise information construction, enterprise informationized talents should be equipped with certain abilities, such as economic analysis ability, enterprise management ability, and master foundation knowledge and skill of electronic information technology and computer. Besides, they are high-grade specialized talents with information system planning, management ability and the ability to obtain and make use of information resources.

Because the current talent training mode just highlight professional theory system of systematic and integrity and pay attention to teach the specialized knowledge but neglect to train students' economic analysis ability, management ability, solving practical problems and the innovation ability. The more important one is that separate themselves from enterprise actual demand. Therefore, in enterprise informatization, the computer professionals often showed they are lack of economic analysis ability and organization and management ability; Although the management professionals with management knowledge, economic analysis ability and other strength, they are lack of the corresponding skills and knowledge of science and technology frequently when they are engaged in the informatization works. What's more, they can't combine the theory and practice and 
their comprehensive strength is relatively weak.

The university as the important base of cultivating the talents, when facing with the new situation in the domestic and overseas, we should adapt to the requirement of the development of times to deeply research the question of talent training in the process of informatization development. At the same time, the school needs to optimize the talent training structure and innovation talent training mode. The university-industry collaboration as the foundation, it impulses the educational and teaching reform and improves the quality of teaching. Our goal is to cultivate and produce a group of excellent informationalization talents with adaptability

\section{The Research of University-Industry Collaboration Mode}

In 2001, World Association for Cooperative Education explains that: "Cooperation education combines the learning in the classroom and work, students apply the theoretical knowledge to the practical work that related, working for real employers and getting paid generally. Then, bring the challenges that encountered in the work and experiences back to class, and it even can help students analyze and ponder question further in the study [1].”

School-enterprise cooperation is a cooperative organization that the enterprise and school as the main part and is based on the common interests. What is more, its premise is resources sharing or complementary advantages and through the exchange information and materials to achieve the common goals [2]. In the university-industry collaboration education mode contained system, the basic elements are the environment of school and society and education resources. The basic condition is the cooperation of school and regional social sectors and the basic way of system implementation is the rotate between engineering practice and professional learning. Industrial departments reflect the social demand for talents cultivation in time and through the cooperation to impulse the process of the cultivation of talents are the basic requirements [3].

Therefore, university actively explores the university-industry collaboration mode about enterprise informatization talents should base on the enterprises demand of informatization talents to deduce the informatization application talents cultivation system, as shown in fig.1. According to the present informationalization talents demand for enterprise, we shall confer the knowledge and skill that students need to be equipped and then work out the teaching plans and curriculum system. Establish the international, practical and personalized training goal, through the strategy of "Leapfrog development and open innovation" to achieve the objective that makes the "cultivation of students", "training of teachers" , "cooperation between school and enterprises" and "continuous improvement" can't be separated from each other. In addition, construct the practice base in and around the school to complete the design and practice for University- Industry joint school-running mode.

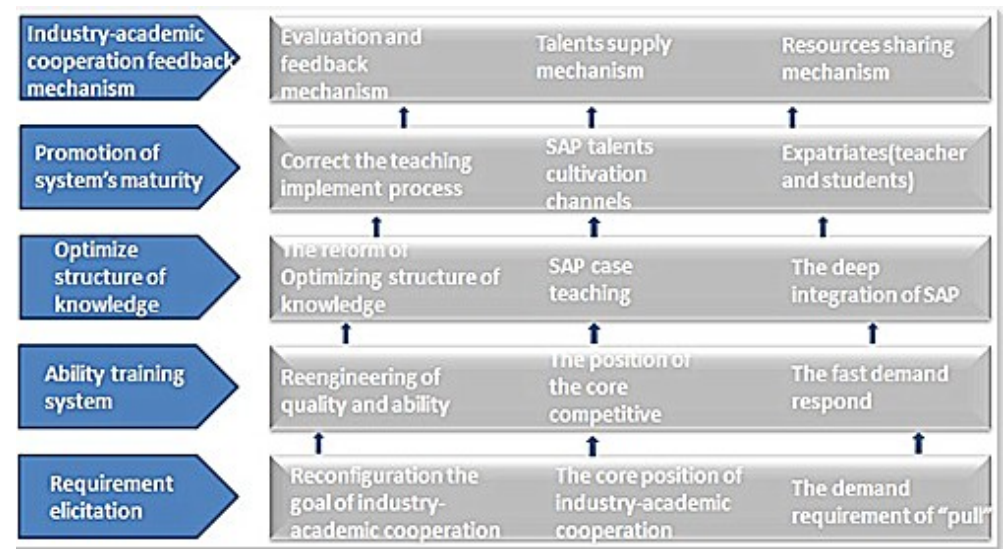

Fig.1. university-industry collaboration mode research of ERP Informatization talents training

New-style ERP informationalization talents cultivation is the university-industry collaboration strategy goal that with "leapfrog development and open innovation": To use "cultivation of students" as the goal and information-based teaching innovation as the key point to reform curriculum system and cultivate the application informationalization talents who can go directly to 
work in the enterprise; To use "cultivation of teachers" as the goal to cultivate the brand consultant teachers who walk at the forefront of information technology implementation; To use the "university-industry collaboration" as the goal to establish the operating system of the courses, textbook, evaluation of the Students and substituted post exercitation together with various powerful ERP enterprises; To use "continuous improvement" as the goal to establish steadily and accurately. What we want to achieve is that staged teaching achievements and university-industry collaboration experiences and lessons summed up in cycle of work content.

By studying the enterprise informationalization present situation in our country, talents demand and talents training goal orientation theory we can modify the traditional method of instruction design. Facing those problems that the curriculum is out of line with the enterprise demand, dated textbook content, no occupational and practicalness and students are lack of skills to design a set of ERP talents cultivation program. This program should be guided by market demand and make a good way to improve student's capacity, knowledge and skill. As shown in fig.2.

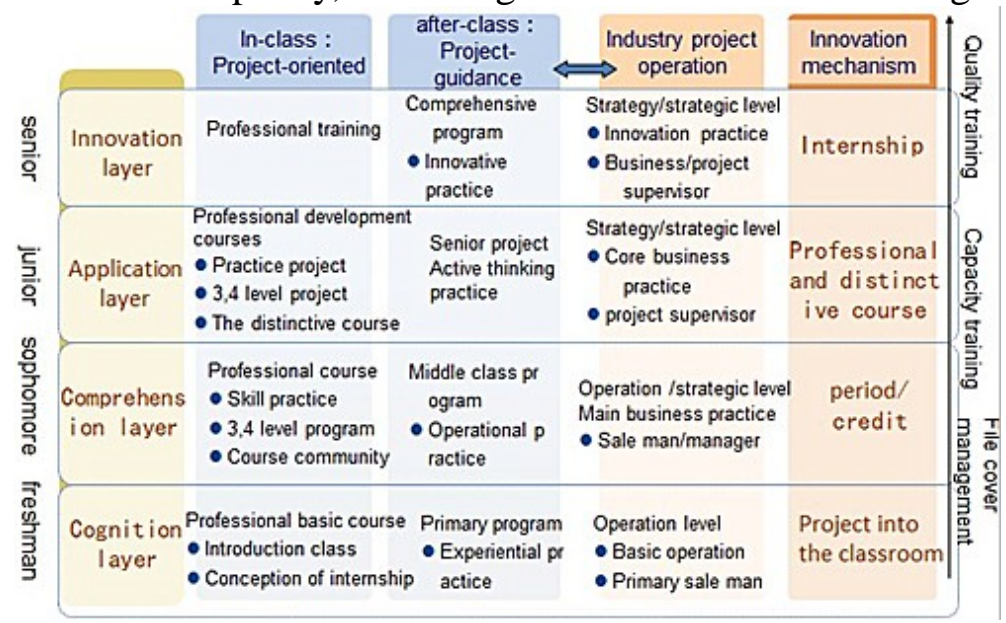

Fig.2. ERP Personnel cultivation program

According to the cultivation ideal of "optimizing the foundation, improving quality and developing innovation" and basing on cultural quality education, we need to strengthen professional quality education, physical quality education and innovation quality education. When students as the internship in the cooperative enterprise, they can exercise their team cooperation ability, anti-pressure ability communication ability, and sense of responsibility and innovation spirit, those abilities cultivate the application talents and let them adapt the enterprise demand.

Rely on goal and demand of the university-industry collaboration mode that acquired ERP application talents, under the ERP industry oriented innovation ability training system to design the university-industry collaboration process about informationalization talents cultivation. As shown in fig.3. Through the school-enterprise cooperation platform, the enterprises will achieve the technological advance and take in increasing elites who graduated from the university. At the same time, school can also obtain extensive educational resources to come true the "win-win" situation between school and enterprise [4].

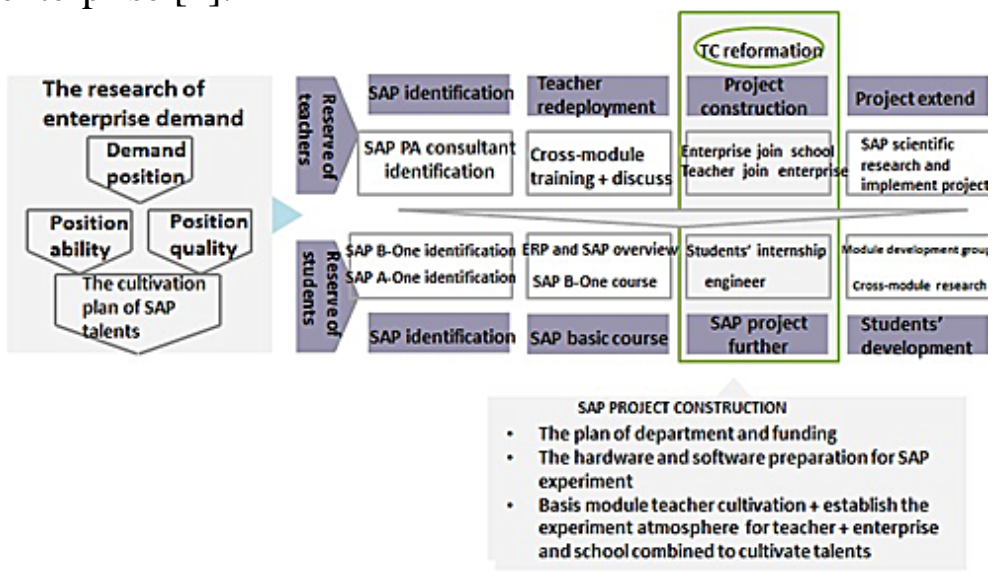

Fig.3. The university-industry collaboration process about informationalization talents cultivation 
Using many kinds of teaching methods and platforms to establish the "SAP ERP" knowledge system and design the " $3+1$ " project practice. Through knowledge reserves in theoretical term, skills upgrading in practice term, research and development center project practice semester co-operative expatriate training and practice to form the channel that cultivate the application informatization talents and a large of talents who mastered in application development skills. As shown in fig.4.
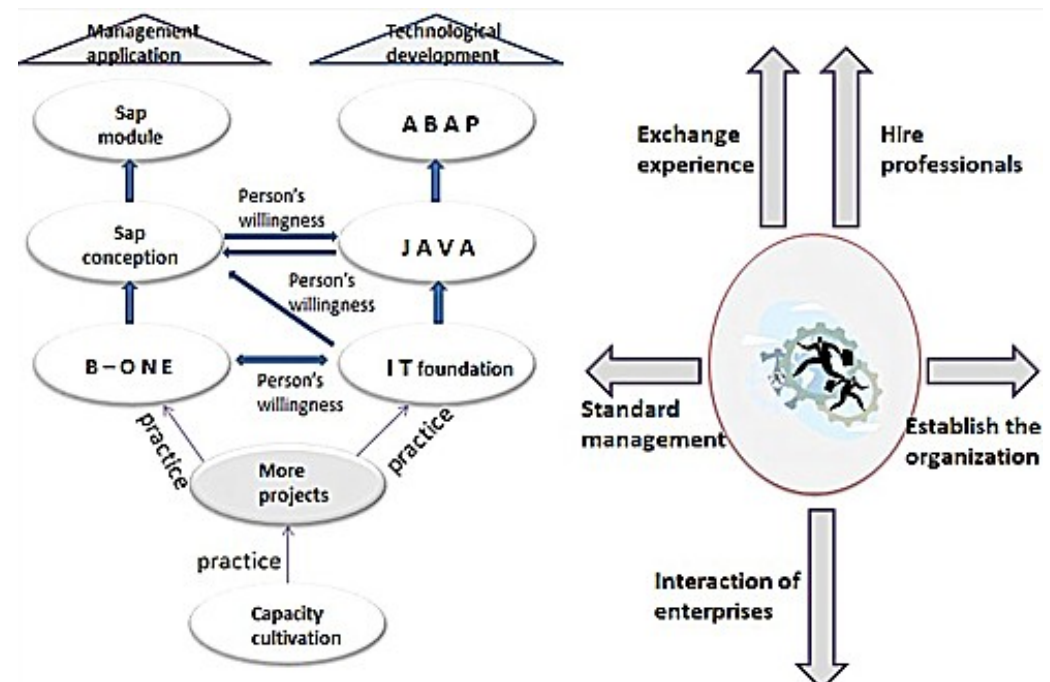

Fig.4. Training channels for "SAP ERP” application informatization talents

\section{Conclusion}

The university-industry collaboration is the basic approach to solve the contradiction between supply and demand that informatization enterprise and higher education school. In 17th China Communist Party Congress, we must establish the technology innovation system that the enterprise as the subject, the market as the guidance and uniting the industry, school and research. Meanwhile, it is necessary to guide and support innovation elements to the enterprises and promote the scientific achievements transfer them into practical productivity [5]. This article researched the university-industry collaboration mode that facing to the ERP application talents cultivation, in finally, we achieved a "win-win situation" between school and enterprise.

\section{References}

[1] B.M. Hou, “The Research and Practice of University-Industry Collaboration Education”, Vocational Education Research, vol. 12, pp. 55-56, 2007.

[2] G.L. Liu, and Y.Q. Ma, and Y.C. Fan, The research of complex system analysis about operation law for the school-enterprise cooperation's creative platform, Forum on Science and Technology in China, vol. 10, pp. 99-101, 2008.

[3] Z.J. Zhou, and J.W. Sun, and G.L. Guo, “On Deepening Cooperation Between Teaching and Production in Colleges and Universitie”, JOurnal of Jixi University: Comprehensive Edition, vol. 11, pp. 7-8, 2011.

[4] Y.H. Mu, "Reform and Practice of Curriculum Based on the Ideas of Three Double", Technological Development of Enterprise, vol. 29, pp. 112-115, 2010.

[5] Y.M. Li, "Based on the Research of University-Enterprise Cooperation on the Perspective of Strategic Alliance Development”, Science \& Technology Progress and Policy, vol. 26, pp. 8-10, 2009. 